\title{
Economic evaluation. Part 2: Frameworks for combining costs and benefits in health care
}

\author{
Emma McIntosh, Ramon Luengo-Fernandez
}

\section{Introduction}

The first article ${ }^{1}$ in this two-part series on the economic evaluation of health care interventions examined the key concepts of economic evaluation in health care, and the methodological issues pertaining to identification, measurement and evaluation of costs and benefits. The aim of this article is to examine how the costs and benefits previously identified can be brought together within the framework of an economic evaluation.

The three principal economic evaluation techniques are: cost-effectiveness analysis (CEA), cost-utility analysis (CUA) and cost-benefit analysis (CBA). The technique(s) chosen will generally be determined depending on whether the question being addressed is concerned with allocative efficiency or technical efficiency. An allocative efficiency question is concerned with 'whether' to allocate resources to a given programme. All health care programmes have to compete for scarce health care resources. These 'competing' health care programmes may include, for example, family planning clinics, home visiting services, asthma clinics, rheumatology clinics and elective surgery for hernia repair. An allocative efficiency question would be: Should there be increased neonatal scanning services or increased provision of elective hernia repair surgery? In contrast, technical efficiency is concerned with "within programme' efficiency, namely how best to provide a given service. The resources, or budget allocated to a programme, are taken as given and the issue is simply 'how best' to provide that service. A technical efficiency question would be: When providing care for patients with a miscarriage, is surgical, medical or expectant management the most costeffective option?

Economic evaluations are often undertaken alongside randomised controlled trials (RCTs) in which the health care (and sometimes non-health care) resources consumed by patients are evaluated in tandem with the estimation of health outcomes. However, more recently, more economic evaluations are being carried out using a combination of multiple sources of information both for outcomes (clinical trials, observational studies, cohort studies, public health statistics, epidemiological data and preference surveys) and for resource use and costs. This evidence is then synthesised using decision analytic modelling. A section on this approach is provided later.

Before moving on to the main theme of this article, Box 1 provides a useful reminder of some of the economic evaluation terms employed in the previous article.
J Fam Plann Reprod Health Care 2006; 32(3): 176-180 (Accepted 10 March 2006)

Health Economics Research Centre, University of Oxford, Department of Public Health, Oxford, UK

Emma McIntosh, MSc, PhD, Senior Research Officer

Ramon Luengo-Fernandez, MA, MSc, Research Officer

Correspondence to: Dr Emma McIntosh, Health Economics Research Centre, University of Oxford, Department of Public Health, Old Road Campus, Headington, Oxford OX3 7LF, UK. E-mail: emma.mcintosh@dphpc.ox.ac.uk

\section{Bringing costs and benefits together within an economic evaluation framework}

As outlined above, there are three main frameworks for combining costs and benefits within an economic evaluation framework in health care: CEA, CUA and CBA. Which method is used depends upon the outcomes being measured and, more often than not, depends upon the evaluation context. For example, within an RCT it is often difficult to choose the economic evaluation framework in advance, ${ }^{2}$ as there may be a large number of possible outcomes including effectiveness and utility measures whose results cannot be predicted in advance of completion of the trial. However, this article will introduce the concept of the cost-effectiveness plane, a method that, despite its name, allows researchers to present economic cost and benefit data from all three economic evaluation frameworks.

\section{Cost-effectiveness analysis (CEA)}

CEA can, in theory, only be used to address questions of technical efficiency. It examines the effects of at least two competing alternatives 'within a fixed budget'. Such effects are measured in natural unidimensional terms related to the objective of the programme being evaluated (i.e. life years saved, heart attacks prevented, disability days avoided, asthma-free days, percentage reduction in cholesterol concentration, improvement in limb function, and so on).

Recent advances in health economics have seen the reporting of CEA in terms of incremental CEA, whereby a ratio for the extra costs and benefits of an alternative is produced, the numerator being the difference in costs and the denominator the difference in health effect between the two interventions. The incremental cost-effectiveness ratio (ICER) produced is, therefore, a measure of 'extra cost per extra unit of effect' (i.e. ICER = the difference in the mean costs of the two interventions being investigated, divided by the difference in the mean outcomes of the two interventions). However, even once the ICER has been calculated, in order to decide if the

$\begin{array}{|ll|}\begin{array}{l}\text { Box 1: Glossary of useful terms } \\ \text { Economic } \\ \text { evaluation }\end{array} & \begin{array}{l}\text { A comparative analysis of at least two health } \\ \text { interventions used to assess both the costs and } \\ \text { consequences of the different health interventions, } \\ \text { providing a decision framework. }\end{array} \\ \begin{array}{ll}\text { Quality-adjusted } \\ \text { life years (QALYs) }\end{array} & \begin{array}{l}\text { A measure of health outcome that assigns to each } \\ \text { death) to 1 (perfect health) corresponding to the }\end{array} \\ & \begin{array}{l}\text { health-related quality-of-life of that health state. } \\ \text { These values are then aggregated across all the } \\ \text { relevant health states. }\end{array} \\ \begin{array}{l}\text { Stated preference } \\ \text { discrete choice } \\ \text { experiment } \\ \text { (SPDCE) }\end{array} & \begin{array}{l}\text { A methodology based on the premise that any } \\ \text { good or service can be described by its attributes. } \\ \text { The extent to which an individual values that } \\ \text { service or good will depend on the trade-offs made } \\ \text { between levels of these attributes. }\end{array} \\ \begin{array}{ll}\text { Willingness to pay } \\ \text { (WTP) }\end{array} & \begin{array}{l}\text { The process in which individuals are asked the } \\ \text { maximum they are willing to pay, in monetary } \\ \text { terms, to achieve a given benefit of an } \\ \text { intervention/service. }\end{array}\end{array}$


new intervention is cost-effective (or good value for money), there remains a requirement for a judgement to be made as to how much decision makers are willing to pay per extra unit of effectiveness. ${ }^{3}$ As outlined in the first article $^{1}$ in the area of family planning and reproductive health, effectiveness measures may include number of live births achieved, number of pregnancies avoided, breastfeeding weeks, gynaecological infections avoided, and so on. For example, in comparing the extra costs and effectiveness of in vitro fertilisation (IVF) treatment with 'no fertility treatment', the ICER may represent the 'extra cost per extra live birth achieved'. One useful way of presenting the results from CEA (and indeed from CUA and CBA) is by using the costeffectiveness plane. The cost-effectiveness plane is used to represent graphically the relevant dimensions of an economic evaluation (Figure 1).

The difference in effectiveness between alternative interventions, a comparator and a new treatment, for example, is plotted along the horizontal axis, and the difference in cost on the vertical axis. In the SE and NW quadrants, one intervention is clearly more effective and less costly than the other and therefore this intervention would be a clear winner in cost-effectiveness terms. In the SW and NE quadrants, however, the decision is a trade-off concerning the extra cost of additional effectiveness, and the maximum acceptable level of cost-effectiveness becomes a matter of judgement. The results from all methods of economic evaluation can be plotted graphically on the cost-effectiveness plane.

\section{Cost-utility analysis (CUA)}

In health economics, CUA has become synonymous with the quality-adjusted life years (QALY) framework, outlined in the previous article. CUA is similar to CEA in that health effects are the main focus. However, the main difference is that CUA incorporates utilities in its outcome measure and therefore outcomes are represented in terms of QALYs. CUA can, therefore, be seen as an improvement on CEA as it attempts to combine more than one outcome measure, and takes account of both quality and quantity of life. One reason for the development of the QALY framework was so that comparisons could be made across different health care interventions in different clinical areas (i.e. so that allocative efficiency questions could be addressed). In this way, those interventions having the lowest additional cost per additional QALY gained should be prioritised so as to

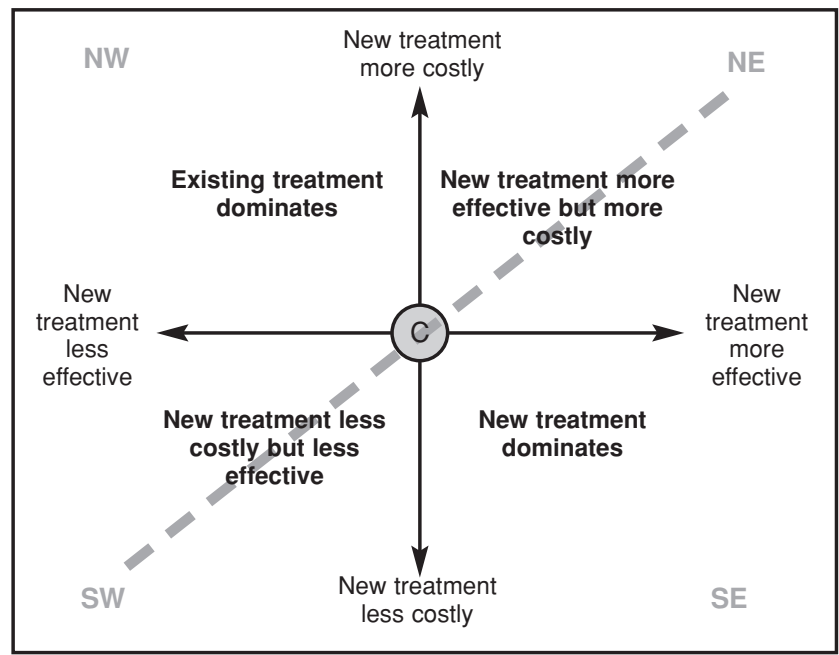

Figure 1 Diagrammatic representation of the cost-effectiveness plane. $C$, comparator

\begin{tabular}{|ll|}
\hline Box 2: Overview of economic evaluation frameworks \\
$\begin{array}{l}\text { Cost-benefit } \\
\text { analysis (CBA) }\end{array}$ & $\begin{array}{l}\text { An economic evaluation whereby both costs and } \\
\text { effects of an intervention are expressed in } \\
\text { monetary terms. Effects are valued in monetary } \\
\text { terms using peoples observed or stated } \\
\text { preferences (e.g. WTP or SPDCE). }\end{array}$ \\
$\begin{array}{ll}\text { Cost-effectiveness } \\
\text { analysis (CEA) }\end{array}$ & $\begin{array}{l}\text { An economic evaluation in which the effects of } \\
\text { different interventions are measured using a single } \\
\text { outcome, expressed as a natural unit (e.g. life years } \\
\text { gained). Alternative interventions are then }\end{array}$ \\
$\begin{array}{l}\text { compared in terms of incremental cost per unit of } \\
\text { effect. }\end{array}$ \\
$\begin{array}{ll}\text { An economic evaluation in which the effects of } \\
\text { different interventions are measured using utility } \\
\text { analysis (CUA) }\end{array}$ \\
$\begin{array}{l}\text { units (e.g. QALYs). Alternative interventions are } \\
\text { then compared in terms of incremental cost per }\end{array}$ \\
QALY.
\end{tabular}

maximise the number of QALYs gained from a given health care budget. However, such comparisons across health interventions can only be made when generic QALYs are used, such that alternative health care interventions can be compared on the same dimension. As with CEA, cost and QALY differences between the two interventions being compared are reported in terms of incremental ratios; in the case of CUA, this ratio is referred to as an incremental cost-utility ratio. Incremental cost-utility ratios can also be represented using the cost-effectiveness plane outlined above, whereby 'utility' is the measure of effectiveness. The use of CUA is the favoured methodology of the National Institute for Health and Clinical Excellence (NICE) ${ }^{4}$

\section{Cost-benefit analysis (CBA)}

CBA is commonly used to address allocative efficiency, though it can also be used to address technical efficiency. It requires all costs and benefits to be measured in commensurate units, usually money. Costs can then be directly compared with benefits. CBA is the only form of evaluation that addresses the question of whether a particular intervention is 'worthwhile' (i.e. whether the benefits of a programme or intervention exceed its cost). As outlined in the previous article, monetary benefits are commonly measured using the 'willingness to pay' (WTP approach $)^{5-10}$ or the 'stated preference discrete choice experiment' (SPDCE) method.$^{7,11-16}$ Basically, the goal of the CBA framework is simply to identify whether an intervention's net benefits exceed its costs. Whilst it may be tempting to label cost savings as 'benefits', this is misleading and such analyses are considered cost analyses. Indeed Zarnke et al. found that $60 \%$ of studies claiming to be CBA were actually cost comparisons where no attempt had been made to value the benefits in monetary terms. ${ }^{17} \mathrm{CBA}$ is broader in scope than CEA and CUA because its monetary valuation of benefits does not restrict it to valuing and comparing programmes in health care only. Indeed, the CBA framework can be used to compare health and non-health programmes across government sectors. ${ }^{18}$ There are a number of inherent difficulties with the WTP method, not least the ethical objection to measuring health in monetary terms. Despite its solid grounding in economic theory, a number of researchers have called for further research into many aspects of this methodology. 19,20 Box 2 provides an overview of the types of economic evaluation frameworks discussed.

The next section introduces the concept of using decision analytic modelling methods to bring costs and benefits together into a framework. 


\section{HEALTH ECONOMICS}

\section{Economic evaluation using decision analytic modelling}

Decision analytic modelling is used widely in the economic evaluations of health care technologies and pharmaceuticals. The purpose of decision analytic modelling is to structure evidence on clinical and economic outcomes in a form that can help to inform decisions about clinical practices and health care resource allocations. Decision analytic models use specialised decision tree software or spreadsheets to synthesise evidence on health benefits and costs from many different sources, including data from clinical trials, observational studies, cohort studies, public health statistics, epidemiological data and preference surveys. Decision analytic models provide a means of combining this evidence together in a formal economic evaluation. For decisions about resource allocation, the end result of a model is often an estimate of cost-effectiveness or cost per QALY gained. A good introduction to the use of economic evaluation using decision analytic modelling can be found in Briggs and Sculpher ${ }^{21}$ and Drummond et al. ${ }^{22}$

\section{Economic evaluation and family planning and reproductive health}

There have been a number of economic evaluations in the area of family planning and reproductive health. ${ }^{23-37}$ Petrou et $a l .{ }^{25}$ highlighted the lack of methodologically robust economic analyses in the area of alternative modes of birth and demonstrated that much of the evidence that is presented in the medical literature is of poor methodological quality and does not exhibit a clear understanding of economic issues. However, the area of the cost-effectiveness of IVF and embryo transfer has recently attracted greater interest and there are a number of economic evaluations in this area. ${ }^{23,27,34,36,38-42}$ In their systematic review of economic evaluations carried out in this area, Garceau et al..$^{23}$ conclude by saying that "future economic appraisals of assisted reproductive techniques would benefit from more robust methodology than is evident in much of the published literature to date". In the next section, examples are provided showing how the CEA, CUA and CBA frameworks have been applied in practice in the area of reproductive health care.

\section{Example of the CEA framework}

Trussell et al. developed an economic model to determine the cost-effectiveness of 15 different methods of contraception (including tubal ligation, oral contraceptives, female and male condoms, cervical cap, withdrawal and periodic abstinence) with no method of contraception. ${ }^{26}$ The main outcome measures of their analysis included 1and 5-year costs, and the number of pregnancies avoided compared with the use of no contraceptive method. For the economic analysis, the authors used the perspective of the third-party payer (e.g. the health service or a private insurance company), and as such only the direct medical costs were included in the analysis. These costs included: (1) method use costs (such as the costs of condoms, tubal ligation, etc.), (2) side effect costs (including costs such as uterine perforation as a result of copper- $T$ intrauterine device (IUD) implantation) and (3) costs of unintended pregnancy (including costs incurred from time of conception until pregnancy termination, such as ectopic pregnancies, spontaneous abortions or term delivery).

The results of this study showed that all 15 methods of contraception were dominant over no method of contraception (i.e. they were all both more effective and less costly than no method of contraception). Over 5 years, the copper-T IUD, vasectomy and the contraceptive implant were the dominant alternatives, saving in excess of US\$13 000 and preventing 4.2 pregnancies, as opposed to no method of contraception. This study is an example of an economic evaluation, whereby the cost and effects of different interventions are compared with the costs and effects of no method of contraception within a CEA framework. This study was categorised as a CEA as its measures of outcome were natural units (i.e. number of pregnancies avoided). The next example illustrates a similar study, this time, however, reporting its outcomes using QALYs.

\section{Example of the CUA framework}

In a similar fashion as in the CEA above, Sonnenberg et al. developed a model to determine the cost-effectiveness of 13 different methods of contraception compared to non-use of contraception. ${ }^{37}$ The main difference in this study, however, was that the measure of outcome was the QALY, hence both life expectancy and quality of life were measured in a single outcome. To elicit QALYs, the authors used a convenience sample of females who were asked to report utilities for each of the health states relevant to contraception (relevant health states included AIDS, infections, menstrual-related disorders, vaginal delivery, Caesarean section, elective abortion, and so on). For temporary morbidity (i.e. the pregnancy in itself) the disutility values were subtracted to calculate the contribution towards QALYs. For long-term morbidity, disutility values were multiplied with the time spent in that condition to calculate its contribution towards QALYs.

As before, contraceptive methods were dominant over use of no contraception. In comparison to the previous study, however, this study also compared the costeffectiveness of the different types of contraceptive methods. The study found that all contraceptive methods, other than vasectomy and depot medroxyprogesterone acetate (DMPA), were not cost-effective as they were more costly and achieved less QALYs than DMPA. As vasectomy was found to be less expensive and less effective than DMPA, an incremental cost-utility ratio was estimated. The results of the incremental analysis showed that the cost for each QALY gained using DMPA over vasectomy would be US\$18 064. However, to determine if DMPA is a cost-effective contraceptive method over vasectomy depends on how much the decision maker values each additional QALY. If, for example, an extra QALY is only valued at US $\$ 1000$ then this intervention will not be cost-effective; however, if each extra QALY is valued at US $\$ 1$ million then this intervention will be highly cost-effective. If we use the implicit cost-effectiveness threshold at which interventions are deemed cost-effective (i.e. $£ 30000$ per QALY or approximately US\$56 000 per QALY), then DMPA would be a cost-effective method of contraception. This latter approach to 'valuing' health outcomes using monetary terms brings us into the realms of CBA.

\section{Example of the CBA framework}

As with most other areas of health care, the majority of work carried out in reproductive health care using the CBA methodology has been either in the area of detailed costing 43 or benefit assessment, ${ }^{12,44-46}$ and there is very little published work which combines both costs and benefits within a formal CBA framework. ${ }^{11}$ The study by Farquar et al. ${ }^{47}$ was introduced in the first article. ${ }^{1}$ Whilst this study was primarily a cost-effectiveness model, Farquar et al. also conducted a CBA alongside the CEA model. ${ }^{47}$ In this study the costs of vaginal compared to abdominal hysterectomy were ascertained using the WTP 
method. Whilst the results showed that the cost of avoiding one abdominal procedure was NZ $\$ 4577$ per case and the cost of avoiding one vertical incision was NZ\$6263, the WTP estimates revealed that in no case did the valuations for vaginal compared to abdominal nor the avoidance of a vertical incision exceed the extra costs, implying that such procedures were in fact not cost-beneficial.

There is also a small body of work emerging in the area of $\mathrm{CBA}$ in reproductive health care in developing countries. ${ }^{48}$ Much of this work, sponsored by the World Health Organization or The World Bank, is concerned with the country-level burden of illness costs and benefits of the prevention, care and mitigation of HIV/AIDS in addition to maternal mortality issues.

For readers interested in the applying the methodology of CBA in the area of family planning and reproductive health care, a good summary of both the theory and applications of the method can be found in Drummond et al. ${ }^{22}$

\section{Discussion}

In this article we have provided an overview of how the costs and benefits of different interventions are combined together in an economic evaluation, with the 'type' of economic evaluation invariably being decided by the outcome or benefit chosen. As QALYs combine quality and length of life, their use is often preferred in economic evaluations. Furthermore, combining all the effects of an intervention into a single measure such as the QALY enables interventions in different disease areas to be directly comparable, and address allocative efficiency questions in health care as outlined in the first article. ${ }^{1}$ As a result, NICE regards CUA as the method of choice when an economic evaluation of different health interventions is performed. ${ }^{4}$ However, there will be times when a CEA is preferred over a CUA. This may occur when either the interventions under study have little impact on quality of life (e.g. interventions dealing with diseases with very high mortality rates) or when quality of life estimates are difficult to obtain or cannot be obtained reliably. CBA is the only form of evaluation where costs can be directly compared with benefits and the method is directly grounded in theory. 49,50 Recently, the use of CBA in the evaluation of reproductive health care interventions has been recommended; 48 however, their use in economic evaluations has been sometimes regarded as unethical by critics ${ }^{51}$ as health outcomes (such as lives) have to be measured in monetary terms. However, even though this is done explicitly in this framework, in all frameworks a threshold (i.e. the maximum amount paid for an extra unit of effect) determines what is cost-effective or not.

\section{Summary}

In this two-part series on the economic evaluation of different health interventions, the methods for measuring costs and valuing benefits have been outlined and the methods by which the costs and benefits are collated within an economic evaluation framework have been described. Economic evaluation should be seen as a decision-making framework that renders the costs and benefits of any intervention or service explicit. In doing so, informed decisions can be made about the allocation of resources to various programmes. The outcome or benefit measure chosen will decide the actual 'type' of economic evaluation carried out. If a number of outcome measures are chosen, a variety of economic evaluations may be performed and the results used as an aid to decision making. ${ }^{2}$ By ensuring that the opportunity costs of programmes are minimised, this should ensure the maximisation of well-being to society given limited resources.

\section{Acknowledgements}

The Health Economics Research Centre (HERC) obtains financial support from the National Health Service Research Capacity Development (NHSRCD) programme. The views expressed in this chapter are those of the authors and not NHSRCD.

\section{Statements on funding and competing interests}

Funding. None identified.

Competing interests. None identified.

References

1 McIntosh E, Luengo-Fernandez R. Economic evaluation. Part 1: Introduction to the concepts of economic evaluation in health care. J Fam Plann Reprod Health Care 2006: 32: 107-112.

2 Donaldson C, Hundley V, McIntosh E. Using economics alongside clinical trials: why we cannot choose the evaluation technique in advance. Health Econ Letters 1996; 5: 267-269.

3 Briggs A, Fenn P. Confidence intervals or surfaces? Uncertainty on the cost-effectiveness plane. Health Econ 1998; 7: 723-740.

4 National Institute for Clinical Excellence. Guide to the Methods of Technology Appraisal. Oxford, UK: Radcliffe Medical Press, 2004.

5 Donaldson D, Mapp T, Farrar S, Walker A, Macphee S. Assessing community values in health care: Is the 'willingness to pay' method feasible? Health Care Anal 1997; 5: 7-29.

6 Gibb S, Donaldson C, Henshaw R. Assessing strength of preference for abortion method using 'willingness to pay': a useful research technique for measuring values. J Adv Nurs 1998; 27: 30-36.

7 Shackley P, Donaldson C. Should we use willingness to pay to elicit community preferences for health care? New evidence from using a 'marginal' approach. J Health Econ 2002; 21: 971-991.

8 McIntosh E, Donaldson C, Ryan M. Recent advances in the methods of cost-benefit analysis in healthcare: matching the art to the science. Pharmacoeconomics 1999; 15: 357-367.

9 Donaldson C, Shackley P, Abdalla M. Using willingness to pay to value close substitutes: carrier screening for cystic fibrosis revisited. Health Econ 1997; 6: 145-159.

10 Donaldson C, Hundley V, Mapp T. Willingness to pay: a method for measuring preferences for maternity care. Birth 1998; 25: 32-39.

11 McIntosh E. Using discrete choice experiments within a cost-benefit analysis framework: some considerations. Pharmacoeconomics 2006; 24 (in press)

12 Hundley V, Ryan M, Graham W. Assessing women's preferences for intrapartum care. Birth 2001; 28: 254-263.

13 Ryan M, McIntosh E, Dean T, Old P. Trade-offs between location and waiting time in the provision of elective surgery. J Public Health Med 2000; 22: 202-210

14 Hall J, Viney R, Haas M, Louviere J. Using stated preference discrete choice modelling to evaluate health care programs. J Bus Res 2002; 5760: $1-7$.

15 Viney R, Lancsar E, Louviere J. Discrete choice experiments to measure consumer preferences for health and healthcare. Expert Review of Pharmacoeconomics and Outcomes Research 2002; 2 . 319-326.

16 Ryan M, Ratcliffe J, Tucker J. Using willingness to pay to value alternative models of antenatal care. Soc Sci Med 1997; 44: 371-380.

17 Zarnke KB, Levine MAH, O'Brien BJ. Cost-benefit analysis in the health care literature: don't judge a study by its label. J Clin Epidemiol 1997; 50: 813-822.

18 Olsen JA, Donaldson C. Helicopters, hearts and hips: using willingness to pay to set principles for public sector health care programmes. Soc Sci Med 1997; 46: 1-12.

19 Diener A, O'Brien B, Gafni A. Health care contingent valuation studies: a review and classification of the literature. Health Econ 1998; 7: 313-326

20 Olsen JA, Smith R. Theory versus practice: a review of willingness to pay in health and health care. Health Econ 2001; 10: 39-52.

21 Briggs A, Sculpher MJ. An introduction to Markov modelling for economic evaluation. Pharmacoeconomics 1998; 13: 397-409.

22 Drummond MF, Sculpher MJ, Torrance GW, O'Brien B, Stoddart GL. Methods for the Economic Evaluation of Health Care Programmes. Oxford, UK: Oxford University Press, 2005.

23 Garceau L, Henderson J, Davis LJ, Petrou S, Henderson LR, McVeigh E, et al. Economic implications of assisted reproductive techniques: a systematic review. Hum Reprod 2002; 17: 3090-3109.

24 Petrou S, Henderson J. Preference-based approaches to measuring the benefits of perinatal care. Birth 2003; 30: 217-226.

25 Petrou S, Henderson J, Glazener C. Economic aspects of caesarean section and alternative modes of delivery. Best Pract Res Clin Obstet Gynaecol 2001; 15: 145-163.

26 Trussell J, Leveque JA, Koenig JD, London R, Borden S, Henneberry $\mathrm{J}$, et al. The economic value of contraception: a comparison of 15 methods. Am J Public Health 1995; 85: 494-503.

27 Mol BWJ, Bonsel GJ, Collins JA, Wiegerinck MAHM, van der Veen F, Bossuyt PMM. Cost-effectiveness of in vitro fertilization and 
embryo transfer. Fertil Steril 2000; 73: 748-754.

28 Ades AE, Sculpher MJ, Gibb DM, Gupta R, Ratcliffe J. Cost effectiveness analysis of antenatal HIV screening in United Kingdom. BMJ 1999; 319: 1230-1234.

29 Howell MR, Quinn TC, Gaydos CA. Screening for Chlamydia trachomatis in asymptomatic women attending family planning clinics: a cost-effectiveness analysis of three strategies. Ann Intern Med 1998; 128: 277-284.

30 Phillips CJ. Economic analysis of long-term reversible contraceptives: focus on Implanon. Pharmacoeconomics 2000; 17: 209-221.

31 Routh S, Barkat-e-Khuda. An economic appraisal of alternative strategies for the delivery of MCH-FP services in urban Dhaka, Bangladesh. Int J Health Plann Manage 2000; 15: 115-132.

32 Rowley P, Loader S, Kaplan R. Prenatal screening for cystic fibrosis carriers: an economic evaluation. Am J Hum Genet 1998; 63: 1160-1174.

33 Bramley D, Graves N, Walker D. The cost effectiveness of universal antenatal screening for HIV in New Zealand. AIDS 2003; 17: 741-748.

34 Karande VC, Korn A, Morris R, Rao R, Balin M, Rinehart J, et al. Prospective randomized trial comparing the outcome and cost of in vitro fertilization with that of a traditional treatment algorithm as first-line therapy for couples with infertility. Fertil Steril 1999; 71: 468-475.

35 Marciante KD, Gardner JS, Veenstra DL, Sullivan SD. Modeling the cost and outcomes of pharmacist-prescribed emergency contraception. Am J Public Health 2001; 91: 1443-1445.

36 Ola B, Papaioannou S, Afnan MA, Hammadieh N, Gimba S. Recombinant or urinary follicle-stimulating hormone? A costeffectiveness analysis derived by particularizing the number needed to treat from a published meta-analysis. Fertil Steril 2001; 75: 1106-1110.

37 Sonnenberg F, Burkman R, Hagerty C, Speroff L, Speroff T. Costs and net health effects of contraceptive methods. Contraception 2004; 69: 447-459.

38 Van Hooris BJ, Stovall DW, Sparks AET, Syrop CH, Allen BD. Costeffectiveness of infertility treatments: a cohort study. Fertil Steril 1997; 67: 830-836.
39 Van Hooris BJ, Syrop CH. Cost-effective treatment for the couple with infertility. Clin J Obstet Gynaecol 2000; 43: 958-973.

40 Van Hooris BJ, Stovall DW, Allen BD, Syrop CH. Cost-effective treatment of the infertile couple. Fertil Steril 1998; 70: 995-1005.

41 Van Hooris BJ, Barnett M, Sparks AET, Syrop CH, Rosenthal G, Dawson J. Effect of the total motile sperm count on the efficacy and cost-effectiveness of intrauterine insemination and in vitro fertilization. Fertil Steril 2001; 75: 661-668.

42 Van Voorhis BJ, Sparks AE, Allen BD, Stovall DW, Syrop CH, Chapler FK. The efficacy and cost-effectiveness of embryo cryopreservation compared with other assisted reproductive techniques. Fertil Steril 1995; 64: 647-650.

43 Ryan M, Donaldson C. Assessing the costs of assisted reproductive techniques. Br J Obstet Gynaecol 1996; 103: 198-201.

44 Longworth L, Ratcliffe J, Boulton M. Investigating women's preferences for intrapartum care: home versus hospital births. Health Soc Care Community 2001; 9: 404-413.

45 San Miguel F, Ryan M, McIntosh E. Demonstrating the use of conjoint analysis in health economics: an application to menorrhagia. Appl Econ 2000; 32: 823-833.

46 Ryan M, Hughes J. Using conjoint analysis to value surgical versus medical management of miscarriage. Health Econ 1997; 6: 261-273.

47 Farquar C, Brown PM, Furness S. Cost effectiveness of pre-operative gonadotrophin releasing analogues for women with uterine fibroids undergoing hysterectomy or myomectomy. Br J Obstet Gynaecol 2002; 109: 1273-1280.

48 Vlassoff M, Singh S, Darroch JE, Carbone E, Bernstein S. Assessing Costs and Benefits of Sexual and Reproductive Health Interventions (Occasional Report No. 11). New York, NY and Washington, DC: The Alan Guttmacher Institute, 2004; 1-116.

49 Mitchell RC, Carson RT. Using Surveys to Value Public Goods: The Contingent Valuation Method. Washington, DC: Resources for the Future, 1989.

50 Bateman IJ, Carson RT, Day B, Hanemann M, Hanley N, Hett T, et al. Economic Valuation with Stated Preference: A Manual. Cheltenham, UK: Edward Elgar, 2002.

51 Johannesson M, Jonsson B. Economic evaluation in health: is there a role for cost-benefit analysis? Health Policy 1991; 17: 1-19.

\section{Are you interested in getting more involved with the Journal of Family Planning and Reproductive Health Care?}

The Journal is seeking to recruit additional peer reviewers and book reviewers to assist the Journal editorial team. See below for further details of what is involved with these roles.

\section{Peer Reviewers}

If you have a special interest in one or more of the topics covered by the Journal and have some time available to peer review occasional papers in your own area(s) of expertise then perhaps you might be interested in joining the Journal's team of peer reviewers? In common with the majority of other academic journals, peer reviewers offer their services on a voluntary basis. However, if you are a member of the Faculty of Family Planning and Reproductive Health Care then each competed review counts for two (2) continuing medical education (CME) points.

For further information please contact the Editor or e-mail the Journal Editorial Office at journal@ffprhc.org.uk.

\section{Book Reviewers}

The Journal regularly receives books for review and for this it relies on the services of a small team of expert reviewers. Whilst no payment is offered in respect of this role, reviewers do get to keep the books they review thus offering an opportunity to build up the reviewer's own or their departmental book collection.

For further information please contact the Journal's Book Review Editor, Dr Kate Weaver, via e-mail (kate.weaver@lpct.scot.nhs.uk). Please provide your contact details (mail and e-mail addresses), together with a note of any special interests and/or expertise. 